\title{
Influence of Fertilizer Loaded Nanoclay Superabsorbent Polymer Composite (NCPC) on Dynamics of P and N Availability and their Uptake by Pearl Millet (Pennisetum glaucum) in an Inceptisols
}

\author{
Subhas Sarkar ${ }^{* \#}$ and S. C. Datta \\ ${ }^{1}$ Division of Soil Science \& Agricultural Chemistry, Indian Agricultural Research Institute, New Delhi (110 012), India \\ \#Presently: Regional Research Centre, Central Institute of Freshwater Aquaculture, Anand, Gujarat (388 001), India
}

\section{Article History}

Manuscript No. AR647a

Received in $6^{\text {th }}$ February, 2014

Received in revised form $6^{\text {th }}$ April, 2014

Accepted in final form $4^{\text {th }}$ June, 2014

\section{Correspondence to}

${ }^{*} E$-mail: subhas_ssac@rediffmail.com

\section{Keywords}

Nanoclay, superabsorbent, clay/polymer composite, phosphorus, nitrogen

\begin{abstract}
The main aim of this research was to study the $\mathrm{P}$ and $\mathrm{N}$ releasing behaviour from fertilizer loaded nanoclay superabsorbent polymer composite (NCPC) and to test its effectiveness as a carrier of slow release fertilizer using pearl millet (Pennisetum glaucum) as test crop grown under Inceptisols. Results revealed that availability of Olsen $\mathrm{P}, 0.01 \mathrm{M} \mathrm{CaCl}_{2}$-extractable $\mathrm{P}$ and mineral $\mathrm{N}$ in soils increased significantly due to addition of fertilizer as NCPC over conventional fertilizer (CF), at same dose of fertilizer application. Availability of $\mathrm{P}$ and $\mathrm{N}$ in soils receiving low dose of fertilizer (LDF) as NCPC (NCPC-L) was statistically at par with that of high dose of fertilizer (HDF) as $\mathrm{CF}(\mathrm{CF}-\mathrm{H})$, particularly at critical crop growth stages. Addition of NCPC-H resulted in $18 \%$ additional biomass yield and $17 \%$ and $11 \%$ additional $\mathrm{P}$ and $\mathrm{N}$ uptake by pearl millet over CF-H, respectively. Similarly, at LDF, biomass yield, P and N uptake increased to 26, 23 and 16\%, respectively, under NCPC (NCPC-L) treated soils than that in CF (CF-L) treated soil. Significant build-up in different non labile pools of inorganic P fractions (Al-P, Fe-P, occluded-P, Ca-P) was recorded on addition of $\mathrm{CF}$ as compared to NCPC application, irrespective of fertilizer doses.
\end{abstract}

\section{Introduction}

The growth of plants and their quality are mainly a function of the availability of fertilizer and water. Among nitrogen $(\mathrm{N})$ fertilizers, the most widely used one is urea because of its high $\mathrm{N}$ content (46\%) and comparatively low cost of production. However, due to surface runoff, leaching, and volatilization, the utilization efficiency or plant uptake of urea is about 30 $40 \%$ (Ladha et al., 2005) and that of phosphorus (P) fertilizer is about 15-25\% (Malhi et al., 2002). These low use efficiencies cause large economic and resource losses. The loss of urea could cause very adverse environmental problems (Al-Zahrani et al., 2000). On the other hand, it is well established that water-soluble $\mathrm{P}$ is converted to water-insoluble $\mathrm{P}$ after reaction with soil minerals; this results in a decrease of $P$ availability and subsequent reduction in P use efficiency by crop. In this regard, slow-or controlled release fertilizers technologies showed its potential in enhancing nutrient use efficiency by reducing nutrient losses.

Superabsorbents are three-dimensionally crosslinked hydrophilic polymers that are water insoluble, hydrogel forming, and capable of absorbing large amounts of aqueous fluids. Effectiveness of superabsorbent polymers (SAP) in agriculture to improve soil moisture retention capacity and improving plant growth has been assessed in several investigations (Anupama et al., 2007; Singh et al., 2011). In practice, however, it always increases farmers' financial burden, but does not significantly bring an augment of the crops yield if SAP is utilized without supply of fertilizers. Recently, research efforts focused on incorporating fertilizers in to superabsorbent polymeric networks to supply water and nutrients simultaneously through a single formulation (Liang et al., 2007; Zhong et al., 2013). However, these superabsorbents are based on pure polymer, and so they were too expensive and not suitable for saline water and soils (Mohan et al., 2005). When nutrients are loaded into a hydrogel, they are released quickly with high permeability. Therefore, research on the preparation of supersorbent materials with good physical strength and nutrient-holding capacities was initiated. Among the various methods used, the introduction of inorganic clay, such as kaolin (Liang and Liu, 2007), montmorillonite (Lee and Yang, 2004), Attapulgite (Li et al., 2004), mica (Lin et al., 2001) into a pure polymeric network is a promising method for reducing production costs and improving the swelling 
properties and hydrogel strengths. Moreover, it was found that the incorporation of kaolin nanopowder into a superabsorbent polymeric network can decrease the diffusion coefficient of urea release from urea-loaded composite hydrogels (Liang and Liu, 2007). Our previous study (Sarkar et al., 2014) also demonstrated that incorporation of nanosized clay into superabsorbent polymer matrix decrease the rate of nutrient release from fertilizer loaded nanoclay superabsorbent polymer composites (NCPC) in distilled water. The research work on effectiveness of nanoclay superabsorbent polymer composites as a slow release fertilizer is still in a developing stage and need to be studied thoroughly. Thus on the basis of the aforementioned background, the objectives of the present article was to assess the $\mathrm{P}$ and $\mathrm{N}$ release behaviour from fertilizer loaded nanoclay superabsorbent polymer composite (NCPC) in comparison with conventional fertilizer (CF) using pearl millet grown in an Inceptisols.

\section{Materials and Methods}

\subsection{Experimental conditions and treatment details}

A greenhouse experiment was carried out in kharif season, July to September, 2010 at the Indian Agricultural Research Institute (IARI), New Delhi located at $28^{\circ} 37^{\prime}-28^{\circ} 39^{\prime} \mathrm{N}$ latitude and $77^{\circ} 9^{\prime}$ $77^{\circ} 11^{\prime}$ E longitude. Pearl millet (Pennisetum glaucum, variety: Pusa composite-383) was grown in an Inceptisols with $10 \mathrm{~kg}$ capacity ( $7 \mathrm{~kg}$ soil) pots ( 2 plants pot $\left.{ }^{-1}\right)$ under five treatments (three replicates) consisting of control (no NP), high dose of fertilizer (HDF) as NCPC (NCPC-H), low dose of fertilizer (LDF) as NCPC (NCPC-L), HDF as conventional fertilizer$\mathrm{CF}$ (CF-H) and LDF as CF (CF-L). High dose of fertilizer (HDF) corresponds to $\mathrm{N} \& \mathrm{P}_{2} \mathrm{O}_{5} @ 60$ and $40 \mathrm{mg} \mathrm{kg}^{-1}$ soil, respectively, while low dose of fertilizer (LDF) corresponds to $\mathrm{N} \& \mathrm{P}_{2} \mathrm{O}_{5} @ 30$ and $20 \mathrm{mg} \mathrm{kg}^{-1}$ soil, respectively. All the treatments were assigned in a completely randomized design (CRD) and replicated thrice. In all the treatments (including control) $\mathrm{K}_{2} \mathrm{O}$ were applied @ $20 \mathrm{mg} \mathrm{kg}^{-1}$ soil in the form of $\mathrm{KCl}$. To simulate leaching loss of mineral nitrogen in natural field condition we leached each pot at $15^{\text {th }}$ day after sowing the crop with 3.51 of de-ionized water and the leachates were collected in a reagent bottle. The total mineral $\mathrm{N}$ leached from the soil was determined by multiplying the concentration of mineral $\mathrm{N}$ in the leachate and volume of the leachate. The pots were kept weed-free and irrigated on need basis to ensure that water was not a limiting factor. Some of the important physicochemical properties of the experimental soil analyzed by standard methods were: texture sandy loam with sand $69.0 \%$, silt $19.6 \%$ and clay $11.4 \%$ (Jackson, 1973); $\mathrm{pH}_{\mathrm{w}}$ (1:2.5, soil:water) 7.9 (Jackson, 1973); electrical conductivity $\left(\mathrm{EC}_{\mathrm{w}} 1: 2\right.$, soil:water) $0.24 \mathrm{ds} \mathrm{m}^{-1}$ (Jackson, 1973); organic carbon $0.29 \%$ (Walkley and Black, 1934); Olsen phosphorus $13.2 \mathrm{mg} \mathrm{kg}^{-1}$ soil (Olsen et al., 1954); ammonium nitrogen $16.7 \mathrm{mg} \mathrm{kg}^{-1}$, nitrate nitrogen $19.4 \mathrm{mg} \mathrm{kg}^{-1}$ soil (Keeney and Nelson, 1982); P-fixing capacity 25\% (Waugh and Fitts, 1966); available potassium $135 \mathrm{mg} \mathrm{kg}^{-1}$ soil (Hanway and Heidel, 1952).

\subsection{Synthesis of fertilizer loaded NCPC}

The smectite dominated nanoclay was separated from soil of order Vertisols. Then a nanoclay superabsorbent polymer composite (NCPC) was synthesized by copolymerization of partially neutralized acrylic acid, acrylamide and nanoclay (10 wt \%) using ammonium persulphate as radical initiator and N,N'-methylene bisacrylamide as crosslinker. The details on synthesis of NCPC can be seen from our previous study (Sarkar et al., 2014). The loading of the NCPC with urea and di-ammonium phosphate (DAP) were carried out by immersing pre-weighed dry gels into the aqueous solution of respective fertilizer for $20 \mathrm{~h}$ to reach swelling equilibrium. Thereafter, the swollen gels were dried at $60{ }^{\circ} \mathrm{C}$ for 6 days, milled and screened. The component analysis showed that DAP loaded NCPC contained $16.9 \% \mathrm{P}_{2} \mathrm{O}_{5}$ and $6.6 \% \mathrm{~N}$ and urea loaded NCPC contained $17.4 \% \mathrm{~N}$.

\subsection{Sampling, measurements and data analysis}

Sub-samples of soils were drawn by a tube auger from each pot at an interval of 10,20,30, 40, 50 and 60 days after sowing (DAS) and subsequently processed for further analysis. Ammonium- $\mathrm{N}\left(\mathrm{NH}_{4}{ }^{+}-\mathrm{N}\right)$ and nitrate- $\mathrm{N}\left(\mathrm{NO}_{3}{ }^{-} \mathrm{N}\right)$ in soil were estimated by following the procedure given by Keeney and Nelson (1982). Phosphorus from soil samples were extracted with Olsen extractant $\left(0.5 \mathrm{M} \mathrm{NaHCO}_{3}\right)$ and $0.01 \mathrm{M} \mathrm{CaCl}_{2}$ solution (Soil:extractant ration of 1:10) and P-content in the extracts were determined by ascorbic acid method (Watanable and Olsen, 1965). Inorganic P in soil samples was fractionated after harvest of the crop using the procedure developed by Peterson and Corey (1966). Plants were harvested at 60 days after sowing and dry weight recorded after drying them in a hot-air oven till constant weight. Samples were digested in a 2:1 mixture of $\mathrm{HNO}_{3}$ and $\mathrm{HClO}_{4}$ and $\mathrm{P}$ concentration was determined by molybdo-phosphoric acid method. Total nitrogen in plant samples were determined by micro-Kjeldahl method

Experimental data were analyzed following standard statistical methods (Gomez and Gomez, 1984). Data obtained were subjected to analysis of variance (ANOVA) using statistical software MSTATC. The Duncan's Multiple Range Test was used to segregate significance of difference among the mean values.

\section{Results and Discussion}

\subsection{Inorganic $P$ fractions at harvest of the crop}

Among the different inorganic $\mathrm{P}$ fractions, saloid-P, aluminium 
bound-P (Al-P), iron bound-P (Fe-P), occluded-P (O-P) and calcium bound-P (Ca-P) were significantly affected by application of different fertilizer treatments (Figure 1a,b,c,d,e). Data in Figure 1a revealed that saloid-P contents recorded under treatments NCPC-H and CF-H were at par and significantly higher compared to other treatments (control, NCPC-L and CF-L). Further, the concentration of saloid-P in soils treated with NCPC-L and CF-L were at par. Addition of conventional fertilizer (CF-H and CF-L) induced a significant increase in Al-P content of soil as compared to other treatments (Figure 1b). Moreover, CF-H registered significantly higher content of Al-P in soil over CF-L treatment. Similarly, Fe-P content in the soils was not affected on addition of NCPC (NCPC-H and NCPC-L) over control (Figure 1c). Whereas, conventional fertilizer application (CF-H and CF-L) resulted significantly higher $\mathrm{Fe}-\mathrm{P}$ content in the soil as compared to other treatments. Treatment CF-H registered higher Fe-P content in soil than that recorded under treatment CF-L. Occluded-P content measured under CF-H was significantly higher than that of other treatments and remained at par for all other treatments (Figure 1d). Figure 1e showed that addition of CF (CF-H \&

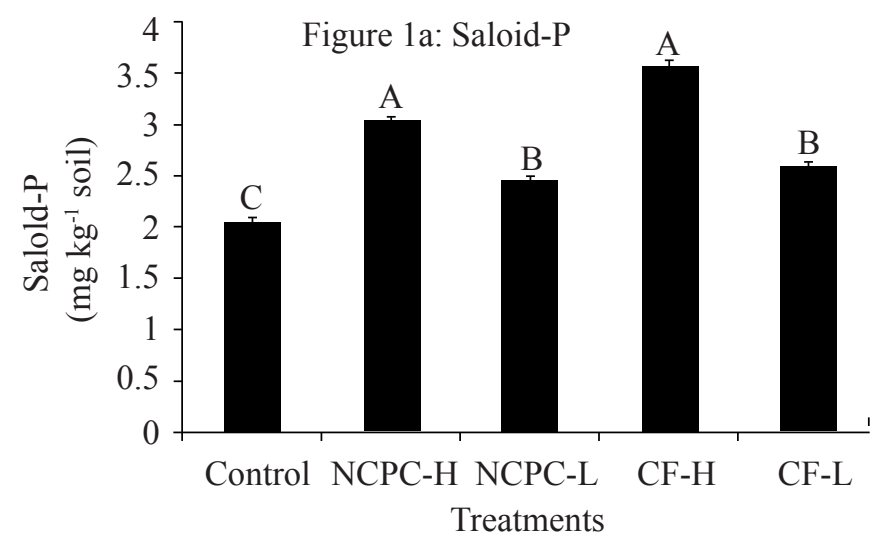

Figure 1: Concentrations of (a) Saloid-P, (b)Aluminium-P (Al-P), (c) Iron-P (Fe-P), (d) Occluded-P (Ocl-P) and (e) calcium bound-P (Ca-P) as affected by different fertilizer treatments in soil (vertical bar stands for standard errors).

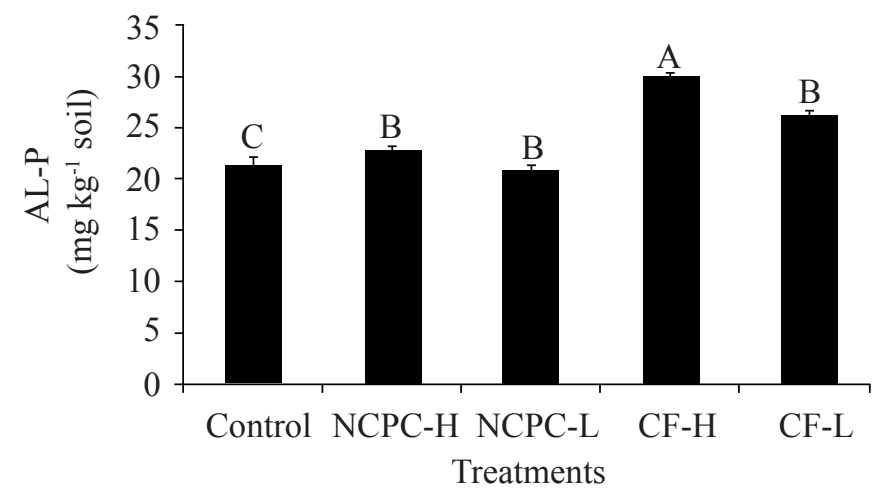

Figure 1b: Aluminium-P (Al-P)
CF-L) registered significantly higher fixation of inorganic $\mathrm{P}$ in to calcium bound form (Ca-P) than that of other treatments. Whereas, NCPC treated soils did not change Ca-P fraction over control. Further, Treatment CF-H induced higher Ca-P content in soil than that in CF-L treatment. In general, the reactions of $\mathrm{P}$ with soils are concentration dependent. This implies that one single application of highly soluble $\mathrm{P}$ is likely to result in a rapid reduction of available forms due to fixation in to soil medium. Addition of highly soluble conventional DAP fertilizer resulted in very high concentration of inorganic phosphate in to soil that

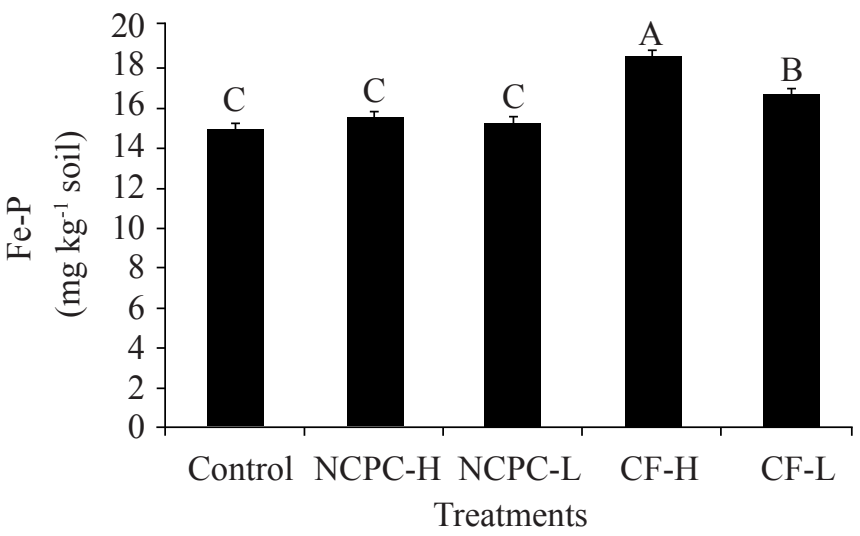

Figure 1c: Iron-P (Fe-P)

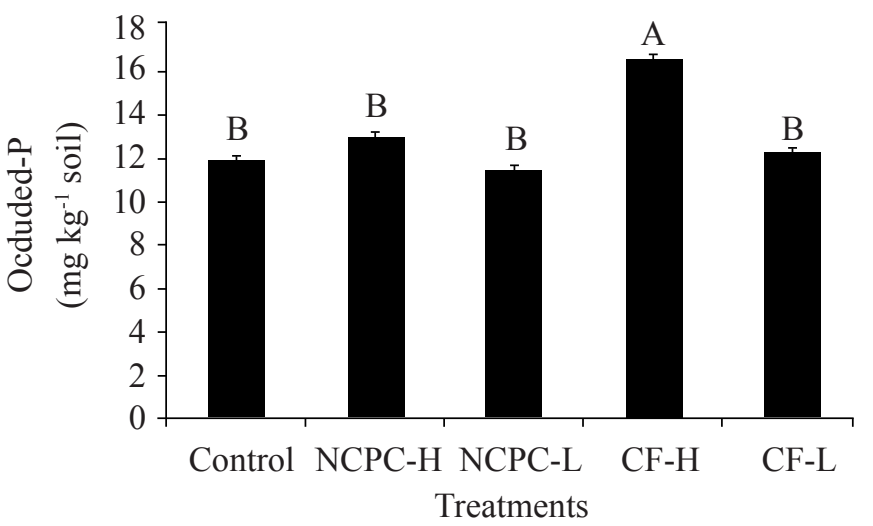

Figure 1d: Occluded-P (Ocl-P)

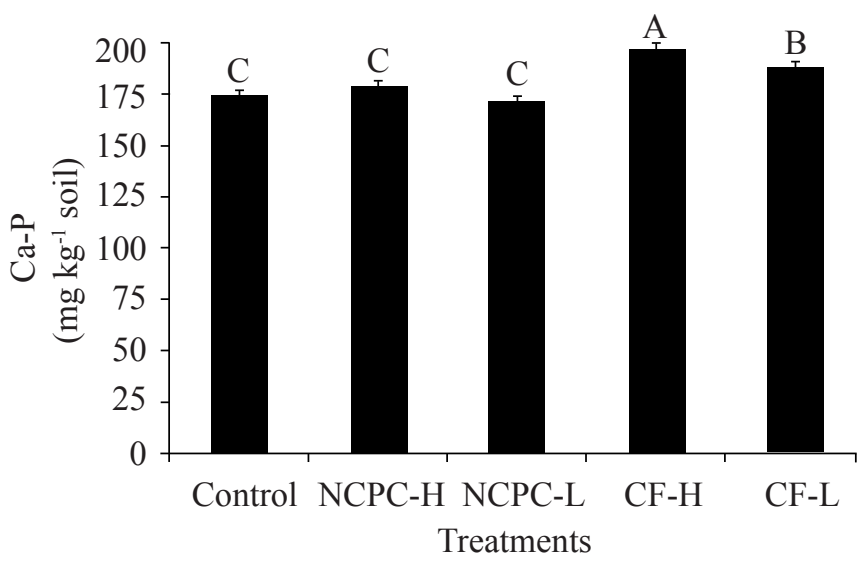

Figure 1e: Calcium bound-P (Ca-P) 
might have contributed to its higher fixation and subsequent increase in non-available inorganic fractions (Shaviv and Schnek, 1989). On the contrary, application of DAP through NCPC resulted in controlled release of phosphate in to soil medium which might have contributed to reduced phosphate fixation.

\subsection{Phosphorus availability}

Lowest amount of Olsen-P and $0.01 \mathrm{M} \mathrm{CaCl}_{2}-\mathrm{P}$ were recorded in control where no $\mathrm{P}$ was added compared to treatments receiving $\mathrm{P}$-fertilization, irrespective of sampling periods (Figure 2a,b). In general, availability of $\mathrm{P}(\mathrm{Olsen}-\mathrm{P}$ and $0.01 \mathrm{M}$ $\left.\mathrm{CaCl}_{2}-\mathrm{P}\right)$ decreased continuously with progress of sampling periods, irrespective of fertilizer treatments, but the rate of decrease was much higher under CF treated soils than that in NCPC treated soils, especially at initial sampling periods. Further, at same dose of fertilizer application, $\mathrm{P}$ availability (Olsen-P and 0.01M CaCl $2-\mathrm{P}$ ) under NCPC treated soil was higher than its corresponding $\mathrm{CF}$ treatment for at least up to 40 DAS. Availability of P under NCPC-L treatment was remained at par with $\mathrm{P}$ availability under $\mathrm{CF}-\mathrm{H}$ treatment at critical crop growth stages (20 to $40 \mathrm{DAS}$ ). Data emanated from the study revealed that soils treated with conventional DAP fertilizer significantly decreased availability of $\mathrm{P}$ in soil as compared to DAP loaded NCPC treated soils (Figure 2a,b). Reduced availability of $\mathrm{P}$ in conventional DAP treated soils attributed to rapid reduction of available $\mathrm{P}$ into insoluble form due to fixation in soil. On the other hand increased availability of $\mathrm{P}$ on addition of NCPC might be due to controlled release of nutrients into fixing medium as reported by previous study (Barrow, 1985). Data recorded on different inorganic $\mathrm{P}$ fractions were in line with the increased $\mathrm{P}$ availability data under NCPC treated soils. Present study showed that NCPC fertilizer worked as a controlled release fertilizer with respect to $P$. This present

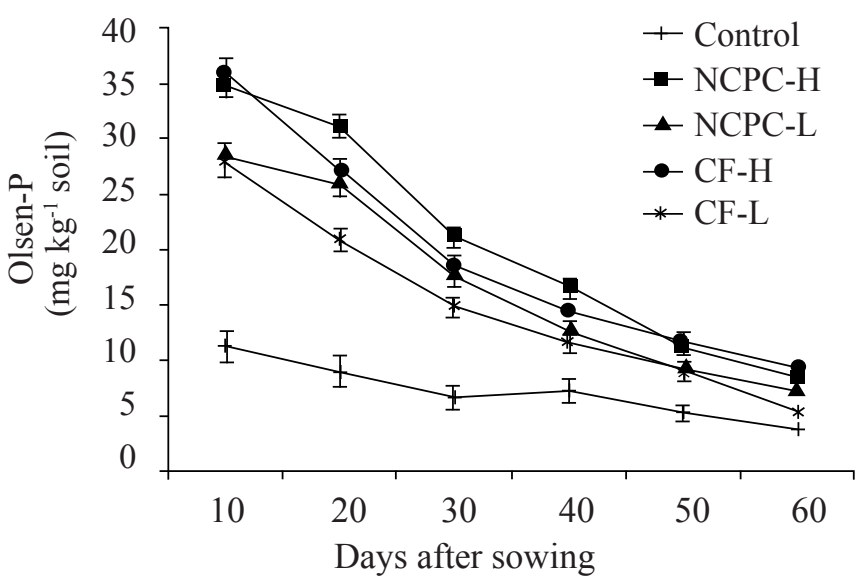

Figure 2a: Olsen-P results corroborate the findings of our previous laboratory study (Sarkar et al., 2014).

\subsection{Mineral $N$ availability}

In general, the concentrations of ammonium- $\mathrm{N}\left(\mathrm{NH}_{4}^{+}{ }^{-} \mathrm{N}\right)$, nitrate- $\mathrm{N}\left(\mathrm{NO}_{3}^{-}-\mathrm{N}\right)$ and total mineral-N in soils decreased with advancement of crop growth and became lowest at harvest of the crop (60 DAS), irrespective of treatments (Figure 3a,b,c). Concentration of $\mathrm{NH}_{4}^{+}-\mathrm{N}$ in soil under NCPC-H remained at par with $\mathrm{CF}-\mathrm{H}$ across the sampling period, except at $30 \mathrm{DAS}$ and 40 DAS when treatment NCPC-H maintained significantly higher $\mathrm{NH}_{4}^{+}$-N in soil than CF-H (Figure 3a). Application of CF-H registered significantly higher amounts of $\mathrm{NH}_{4}^{+}-\mathrm{N}$ in soils over NCPC-L up to 20 DAS and thereafter (30 DAS and 40 DAS), the differences were statistically non-significant. Concentration of $\mathrm{NH}_{4}^{+}-\mathrm{N}$ recorded under NCPC-L treatment was significantly higher than that in CF-L for 30 and 40 DAS and thereafter the differences remained at par. Significantly higher nitrate $\mathrm{N}$ $\left(\mathrm{NO}_{3}^{-}-\mathrm{N}\right)$ in soil was noticed under $\mathrm{CF}-\mathrm{H}$ over $\mathrm{NCPC}-\mathrm{H}$ at 10 DAS, the trend reversed significantly at 20,30 and 40 DAS and remained at par thereafter (Figure 3b). Similarly, treatment CF-L registered significantly higher $\mathrm{NO}_{3}^{-}-\mathrm{N}$ in soil over

Table 1: Pearl millet plant dry matter (DM), plant height (PH), $\mathrm{N}$-concentration (NC), N-uptake (NU), P-Concentration (PC) and P-uptake (PU) at the harvest of crop.

\begin{tabular}{lcccccc}
\hline $\begin{array}{l}\text { Treat- } \\
\text { ments }\end{array}$ & $\begin{array}{c}\mathrm{DM}(\mathrm{g} \\
\left.\text { pot }^{-1}\right)\end{array}$ & $\begin{array}{c}\mathrm{PH} \\
(\mathrm{cm})\end{array}$ & $\begin{array}{c}\mathrm{NC} \\
(\%)\end{array}$ & $\begin{array}{c}\mathrm{NU}(\mathrm{mg} \\
\left.\text { pot }^{-1}\right)\end{array}$ & $\begin{array}{c}\mathrm{PC} \\
(\%)\end{array}$ & $\begin{array}{c}\mathrm{PU}(\mathrm{mg} \\
\left.\text { pot }^{-1}\right)\end{array}$ \\
\hline Control & $12.0^{\mathrm{D}}$ & $66^{\mathrm{D}}$ & $0.53^{\mathrm{B}}$ & $84^{\mathrm{D}}$ & $0.115^{\mathrm{B}}$ & $14.2^{\mathrm{D}}$ \\
NCPC-H & $36.8^{\mathrm{A}}$ & $139^{\mathrm{A}}$ & $0.61^{\mathrm{A}}$ & $223^{\mathrm{A}}$ & $0.140^{\mathrm{A}}$ & $51.6^{\mathrm{A}}$ \\
NCPC-L & $29.6^{\mathrm{B}}$ & $113^{\mathrm{B}}$ & $0.60^{\mathrm{A}}$ & $188^{\mathrm{B}}$ & $0.148^{\mathrm{A}}$ & $42.7^{\mathrm{B}}$ \\
CF-H & $31.4^{\mathrm{B}}$ & $112^{\mathrm{B}}$ & $0.62^{\mathrm{A}}$ & $201^{\mathrm{B}}$ & $0.153^{\mathrm{A}}$ & $44.4^{\mathrm{B}}$ \\
CF-L & $23.6^{\mathrm{C}}$ & $97^{\mathrm{C}}$ & $0.59^{\mathrm{B}}$ & $162^{\mathrm{C}}$ & $0.145^{\mathrm{A}}$ & $34.9^{\mathrm{C}}$ \\
\hline
\end{tabular}

"mean separation within columns by the Duncan's test; $p<0.05$

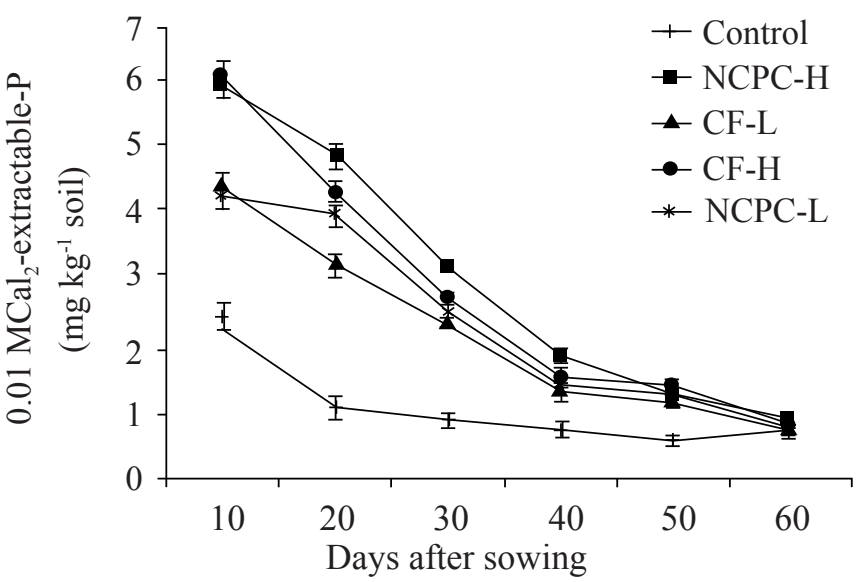

Figure 2b: $0.01 \mathrm{M} \mathrm{CaCl}_{2}$-extractable $\mathrm{P}$

Figure 2: Changes in availability of (a) Olsen-P and (b) $0.01 \mathrm{M} \mathrm{CaCl}_{2}$-extractable-P as affected by different fertilizer treatments (vertical bar stands for standard errors). 
NCPC-L at 10 DAS, remained lower at 20 and 30 DAS and was at par for 40 DAS and onwards. Further, treatment NCPC-L was equally effective in maintaining availability of $\mathrm{NO}_{3}^{-}-\mathrm{N}$ in soil with treatment $\mathrm{CF}-\mathrm{H}$ at 20 and 30 DAS. Figure $3 \mathrm{c}$ depicted that total mineral $\mathrm{N}$ concentration in the soil of the NCPC-H treatment was lower than that in the $\mathrm{CF}-\mathrm{H}$ treatment for the early sampling period (10 DAS). After that time the NCPC-H treatment tended to maintain a higher concentration of total mineral $\mathrm{N}$ in the soil, although the differences were not always statistically significant. Similarly, at early stage (10 DAS) treatment CF-L maintained significantly higher concentration of total mineral N than NCPC-L treatment, thereafter the trend reversed although the differences were not always statistically significant. Moreover, the total mineral $\mathrm{N}$ concentration in the soil of the NCPC-L treatment was remained at par with the total mineral $\mathrm{N}$ concentration in the soil treated with $\mathrm{CF}-\mathrm{H}$ for 30 and 40 DAS.

The leaching loss of mineral $\mathrm{N}$ at 15 days showed that significantly higher mineral $\mathrm{N}$ was lost from soils receiving

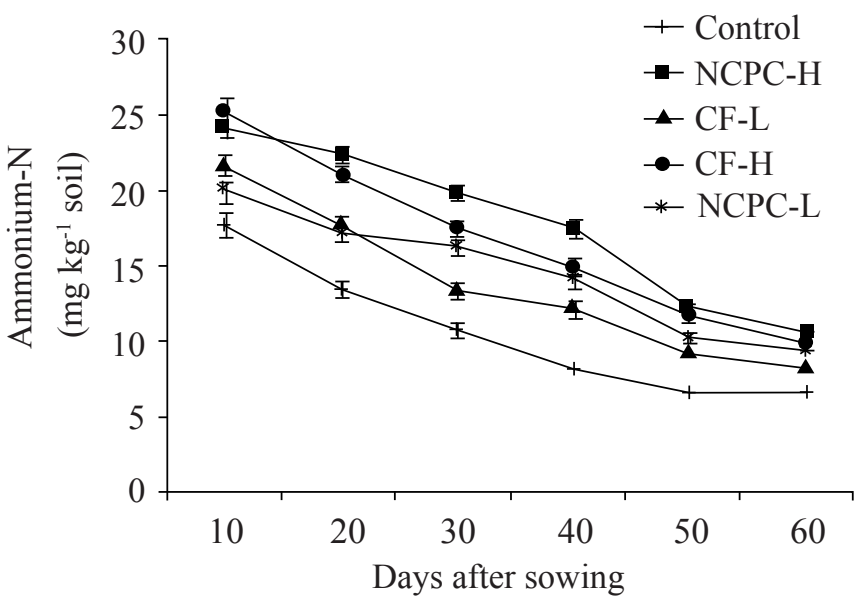

Figure 3a: Ammonium-N

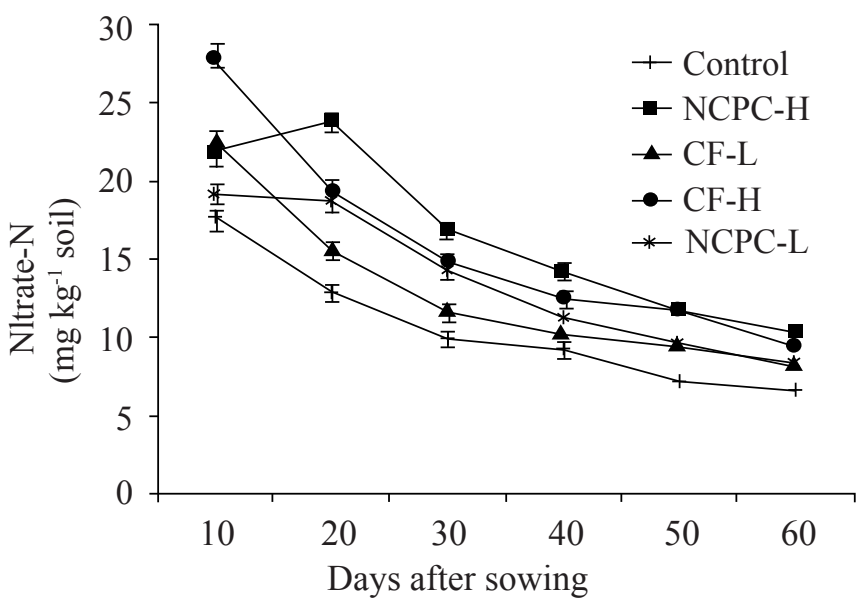

Figure 3b: Nitrate-N conventional $\mathrm{CF}$ as compared to NCPC treated soils, irrespective of fertilizer dose (Figure 4). Further, loss of mineral $\mathrm{N}$ from $\mathrm{CF}-\mathrm{H}$ treated soil was significantly higher than that recorded under CF-L treated soil. Similarly, NCPC-H registered significantly higher leaching loss of mineral $\mathrm{N}$ over NCPC-L. Rapid hydrolysis of urea under conventional fertilizer and subsequent nitrification resulted in higher $\mathrm{NH}_{4}^{+}-\mathrm{N}$ and $\mathrm{NO}_{3}^{-}-\mathrm{N}$ in soils treated with $\mathrm{CF}$ than that in NCPC treated soils, particularly at initial stages. The higher leaching loss of mineral $\mathrm{N}$ under conventional fertilizer resulted lower mineral $\mathrm{N}$ content in soil at middle stages (30 DAS) of crop growth as compared to NCPC treated soils. Mikkelson et al. (1994) also reported reduction in $\mathrm{N}$ leaching loss under controlled release fertilizer (CRF) application. At middle stages of crop growth (30 DAS), nitrate N content was higher in NCPC treated soils as compared to conventional fertilizers. This indicated that NCPC could maintain a gradual release of loaded urea in soil for a longer duration. Chen et al. (2008) also reported that polyolefin coated urea (controlled release) maintained a higher concentration of mineral $\mathrm{N}$ (ammonium) in the soil for longer duration than urea, resulted in increased recovery of fertilizer $\mathrm{N}$. Almost all the treatments were accompanied by a general decrease in total mineral $\mathrm{N}$ at harvest. The extent of decrease, however, was relatively greater under NCPC treated soils as compared to $\mathrm{CF}$ which indicated higher uptake of nutrient in former cases.

\subsection{Biomass yield, plant height and P and $N$ uptake}

Significant increases in biomass yields above the control were recorded on addition of different fertilizer treatments (Table 1). Addition of NCPC-H registered significantly highest biomass yield $\left(36.8 \mathrm{~g} \mathrm{pot}^{-1}\right)$ while the lowest was observed for absolute control $\left(12.0 \mathrm{~g} \mathrm{pot}^{-1}\right)$. Treatment NCPC-H boosted $18 \%$ additional biomass yield over CF-H. Whereas, biomass yield recorded under NCPC-L was $26 \%$ higher than that recorded

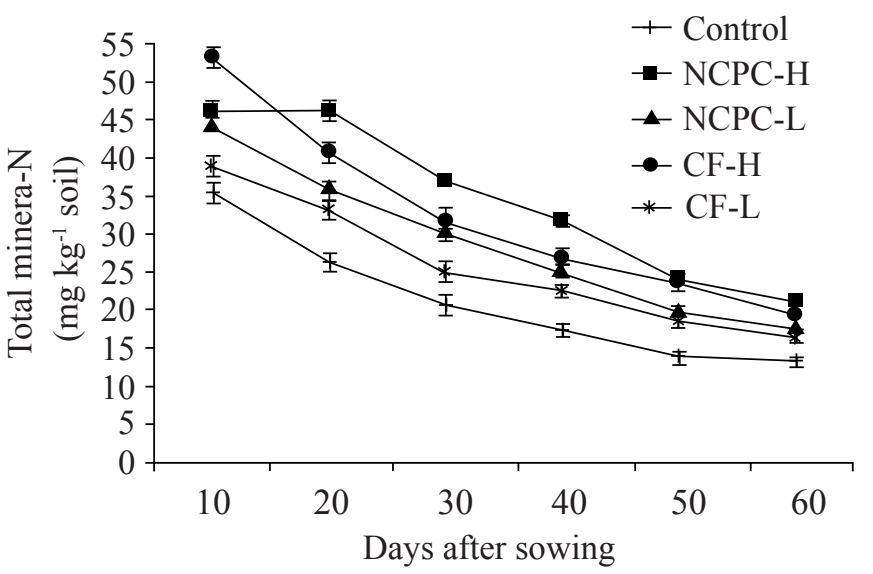

Figure 3c: Total mineral-N

Figure 3: Changes in availability of (a) ammonium-N, (b) nitrate-N and (c) total mineral-N as affected by different fertilizer treatments (vertical bar stands for standard errors). 
under CF-L treatment (Table 1). Biomass yield of pearl millet under NCPC-L (29.6 g pot $\left.^{-1}\right)$ was at par with biomass yield under CF-H treatment (31.4 $\left.\mathrm{g} \mathrm{pot}^{-1}\right)$. Data on plant height of pearl millet followed the same trend as observed for biomass yield (Table 1). Plant height of pearl millet plant ranged from $139 \mathrm{~cm}$ under NCPC-H to $66 \mathrm{~cm}$ for control treatment. Application of NCPC-H induced 25\% higher plant height over CF-H. While, NCPC-L resulted in $17 \%$ higher plant height over plant height recorded under CF-L.

The influence of fertilizer application on $\mathrm{P}$ and $\mathrm{N}$ accumulation in pearl millet was noticeable (Table 1). Application of $\mathrm{P}$ fertilizer either as NCPC or CF induced significant increase in $\mathrm{P}$-content in pearl millet straw, irrespective of fertilizer doses. The P-content recorded under all P-fertilization treatments were at par and varied from $0.140 \%$ (NCPC-H) to $0.153 \%$ $(\mathrm{CF}-\mathrm{H})$. Nitrogen content in pearl millet was unaffected under $\mathrm{CF}-\mathrm{L}$, but increased significantly for all other $\mathrm{N}$-fertilization treatments (NCPC-H, NCPC-L and CF-H) compared to control where fertilizer $\mathrm{N}$ was not added (Table 1). Nitrogen content in the straw varied from $0.53 \%$ under control to $0.62 \%$ under CF-H. Application of NCPC-H, NCPC-L and CF-H were equally effective in maintaining $\mathrm{N}$-content in pearl millet. The maximum uptake of $\mathrm{P}\left(51.6 \mathrm{mg} \mathrm{pot}^{-1}\right)$ and $\mathrm{N}$ (223 $\left.\mathrm{mg} \mathrm{pot}^{-1}\right)$ by pearl millet were obtained in pots where high dose of fertilizer (HDF) was applied as NCPC (NCPC-H). Treatment NCPC-H resulted in $17.0 \%$ and $11.0 \%$ additional uptake of $\mathrm{P}$ and $\mathrm{N}$, respectively, over the $\mathrm{CF}-\mathrm{H}$, while treatment $\mathrm{NCPC}-\mathrm{L}$ resulted in $23.0 \%$ and $16.0 \%$ higher uptake of $\mathrm{P}$ and $\mathrm{N}$, respectively, over the CF-L. Results revealed that application of $\mathrm{P}$ and $\mathrm{N}$ fertilizers as NCPC induced significantly higher uptake of $\mathrm{P}$ and $\mathrm{N}$ than $\mathrm{CF}$, at same dose of fertilizer. Further, uptake of $\mathrm{P}$ and $\mathrm{N}$ measured under treatment NCPC-L and $\mathrm{CF}-\mathrm{H}$ remained at par (Table 1).

Increased availability of $\mathrm{P}$ and $\mathrm{N}$ on addition of fertilizer as NCPC than CF application might have contributed to higher biomass yield and nutrient uptake by pearl millet under NCPC

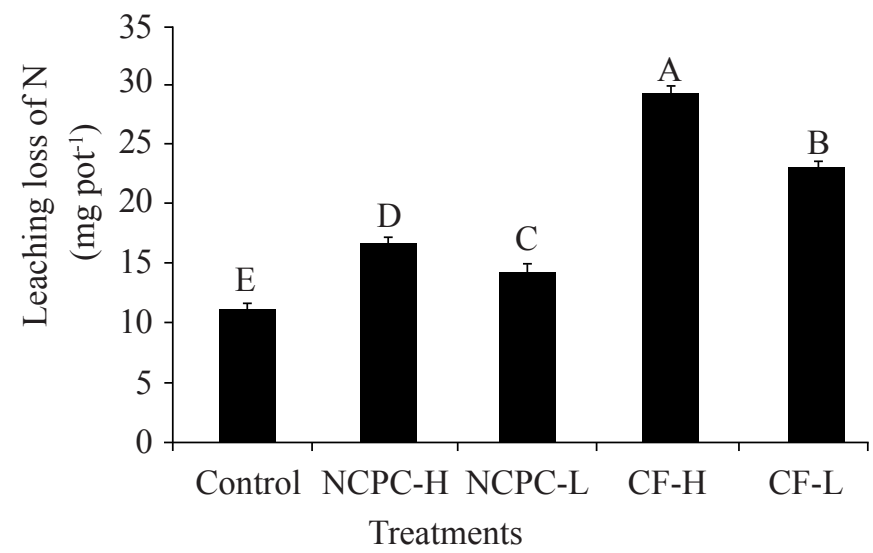

Figure 4: Leaching loss of mineral $\mathrm{N}$ as affected by different fertilizer treatments (vertical bar stands for standard errors) treated soils. Nutrient uptake is an important process, which decides all improvement in plant growth, yield and quality of crop produces. When controlled release fertilizers (CRF) are applied the chemical properties of the soil are improved as compared to conventional fertilizers (Mikkelson et al., 1994) and the utilization of nutrients by plants at critical stages are also increased (Chen et al., 2008) as in CRF the release of nutrients is for an extended period. Hagin and Harrison (1993) also reported that controlled release fertilizer (Agroblen) when used as a source of $\mathrm{P}$, release of phosphorus to the soil medium takes place at rates and contents that allow the growing plant to maintain maximum expression of its genetic capability. Moreover the reduction of nutrient immobilization by the chemical and biological reactions might have enhanced the $\mathrm{P}$ availability to crops (Agroblen) at critical physiological stages, thereby increasing the uptake of phosphorus (Bolan et al., 1993). The use of CRF might have allowed the nutrients to be used more efficiently by plants than soluble conventional $\mathrm{N}$ fertilizers by reducing $\mathrm{N}$ leaching and other losses and providing a constant supply of nutrients to the roots (Mikkelson et al., 1994; Hauck, 1985). Moreover, superabsorbent polymer acts as a micro-reservoir to retain and supply nutrients to crops along with moisture, and thus could increase the utilization efficiency of nutrients and water at the same time (Liang et al., 2007). All the reasons specified above might have enhanced the uptake of $\mathrm{P}$ and $\mathrm{N}$ by pearl millet when fertilizer loaded NCPC was applied to the soils.

\section{Conclusion}

Fertilizer loaded nanoclay superabsorbent polymer composite (NCPC) has a significant effect on biomass yield and nutrients uptake by pearl millet due to higher nutrient availability at critical growth stages. Further, addition of fertilizer as NCPC could save $50 \%$ of fertilizer dose without compromising yield of pearl millet. Thus use of NCPC as a carries of costly nutrients could be an alternative and effective option to save costly chemical fertilizers. Further investigation on combined effect of water holding capacity and slow nutrient release property of the NCPC and the economic analysis are also to be considered as a worthwhile topic for future studies.

\section{References}

Al-Zahrani, S.M., 2000. Utilization of polyethylene and paraffin waxes as controlled delivery system for different fertilizers. Industrial and Engineering Chemistry Research 39, 367-371.

Anupama, Kumar, R., Jat, M.L., Parmar, B.S., 2007. Performance of a new superabsorbent polymer on seedling and post planting growth and water use pattern of chrysanthemum grown under controlled environment. 
Acta Horticulturae 74, 43-50.

Barrow, N.J., 1985. Comparing the effectiveness of fertilizers. Fertilizer Research 8, 85-91.

Bolan, N.S., Hedley, M.J., Loganathan, P., 1993. Preparation, forms and properties of controlled release phosphate fertilizers. Fertilizer Research 35, 13-24.

Chen, D., Freney, J.R., Rochester, I., Constable, G.A., Mosier, A.R., Chalk, P.M., 2008. Evaluation of polyolefin coated urea (Meister) as a fertilizer for irrigated cotton. Nutrient Cycling in Agroecosystem 81, 245-254.

Gomez, K.A., Gomez, A.A., 1984. Statistical Procedures for Agricultural Research. John Wiley and Sons, New York.

Hagin, J., Harrison, R., 1993. Non-acidulated and partially acidulated phosphate rocks as controlled release $\mathrm{P}$ fertilizers. Fertilizer Research 35, 25-31.

Hanway, J.J., Heidel, H., 1952. Soil analysis methods as used in Iowa state college, Soil Testing Laboratory, Iowa Agric 54, 1-31.

Hauck, R.D., 1985. Slow release and bio-inhibitor-amended nitrogen fertilizers. In: Engelstad, O.P. (Ed.), Fertilizer Technology and Use ( ${ }^{\text {rd }}$ Edn.), Medison, WI, 293-322.

Jackson, M.L., 1973. Soil Chemical Analysis. Prentice Hall of India Pvt. Ltd., New Delhi.

Keeney, D.R., Nelson, D.W., 1982. Nitrogen inorganic forms. In: Page, A.L., Miller, R.H., Keeney, D.R. (Eds.), Methods of Soil Analysis. Agronomy monograph 9 Part 2 ( $2^{\text {nd }} E d n$.), American Society of Agronomy, Madison Wisconsin, 643-698.

Ladha, J.K., Pathak, H., Krupnik, T.J., Six, J., Van Kessel, C., 2005. Efficiency of fertilizer nitrogen in cereal production: retrospect and prospects. Advances in Agronomy 87, 85-156.

Lee, W.F., Yang, L.G., 2004. Superabsorbent polymeric materials. XII. Effect of montmorillonite on water absorbency for poly (sodium acrylate) and montmorillonite nanocomposite superabsorbents. Polymers for Advanced Technologies 92, 3422-3429.

Li, A., Wang, A., Chen, J., 2004. Studies on poly (acrylic acid)/attapulgite superabsorbent composites. II. Swelling behaviour of super absorbent composites in saline solutions and hydrophilic solvent mixtures. Journal of Applied Polymer Science 94, 1869-1876.

Liang, R., Liu, M., 2007. Preparation of poly (acrylic acid-coacrylamide)/kaolin and release kinetics of urea from it. Journal of Applied Polymer Science 106, 3007-3017.

Liang, R., Liu, M., Wu, L., 2007. Controlled release NPK compound fertilizer with the function of water retention. Reactive and Functional Polymers 67, 769-779.
Lin, L., Wu, J.H., Yang, Z., Pu, M.L., 2001. Synthesis and properties of poly(acrylic acid)/mica superabsorbent nanocomposite. Macromolecular Rapid Communication 22, $422-424$.

Malhi, S.S., Haderlein, L.K., Pauly, D.G., Johnston, A.M., 2002. Improving fertilizer phosphorus use efficiency. Better Crops 86, 8-9.

Mikkelson, R.L., Williams, H.M., Behel, A.D., 1994. Nitrogen leaching and plant uptake from controlled release fertilizers. Fertilizer Research 37, 43-50.

Mohan, Y.M., Murthy, P.S.K., Raju, K.M., 2005. Synthesis, characterization and effect of reaction parameters on swelling properties of acrylamide-sodium methacrylate superabsorbent copolymers. Reactive and Functional Polymers 63, 11-26.

Olsen, S.R., Cole, C.V., Watanable, F.S., Dean, L.A., 1994. Estimation of available phosphorus in soils by extraction with sodium bicarbonate. USDA Circular 9398, 1-19.

Petersen, G.W., Corey, R.B., 1966. A modified Chang and Jackson procedure for routine fractionation of inorganic soil phosphates. Soil Science Society of America Proceedings 30, 563-565.

Sarkar, S., Datta, S.C., Biswas, D.R., 2014. Synthesis and characterization of nanoclay-polymer composites from soil clay with respect to their water-holding capacities and nutrient-release behavior. Journal of Applied Polymer Science 131(6). doi: 10.1002/app.39951. in press.

Shaviv, A., Schnek, M., 1989. Reactions of a granulated super-phosphate and ammonium sulphate mixtures in calcareous soils. Geoderma 44, 17-27.

Singh, A., Sarkar, D.J., Singh, A.K., Parsad, R., Kumar, A., Parmar, B.S., 2011. Studies on novel nanosuperabsorbent composites: swelling behavior in different environments and effect on water absorption and retention properties of sandy loam soil and soil-less medium. Journal of Applied Polymer Science 120, 1448-1458.

Watanabe, F.S., Olsen, S.R., 1965. Test of an ascorbic acid method for determining phosphorus in water and $\mathrm{NaHCO}_{3}$ extracts from soils. Soil Science Society of America Proceedings 29, 677-678.

Waugh, D.L., Fitts, J.W., 1966. Soil Test Interpretation Studies: Laboratory and Plotted, Plant. Tech. Bull, North Carolina State Agricultural Experiment Station, (ISTP Series) No. 3.

Zhong, K., Lin, Z., Zheng, X., Jiang, G., Fang, Y., Mao, X., Liao, Z., 2013. Starch derivative-based superabsorbent with integration of water-retaining and controlled-release fertilizers. Carbohydrate Polymers 92, 1367-1376. 